\title{
Dijital Teknolojik Gelişim ve Covid 19 Salgınının İstihdam Piyasasına Etkisi*
}

\author{
Digital Technological Development and the Impact of the Covid 19 Epidemic on the Employment Market
}

\author{
Ece Demiray Erol ${ }^{1 * *}$ (D) ibrahim Erol ${ }^{1}$ (D)
}

${ }^{1}$ Department of Economics, Manisa Celal Bayar University, Manisa, Turkey

\begin{abstract}
Received: 29.06 .2021
Accepted: 21.12 .2021

This article was checked by intihal.net

Öz

Dijitalleşme ekonomiyi ve çalışma dünyasını değiştirmekte ve tüm ekonomik sektörleri etkilemektedir. Bu değişimin teknik temeli yeni teknolojilere dayanmaktadır. Bu çerçevede enformasyon ve iletişim teknolojileri, etkili ve güçlü bilgisayarlaşma ile ekonomideki ağ altyapısından hareket edilmektedir. Dijitalleşme yapısal değişimi ve ekonomik büyümeyi etkilemekte, iş dünyası için bir şans yaratmaktadır. Bu amaç doğrultusunda devletin görevi hem iş dünyasına bu yeni teknolojileri destekleyecek ortamı yaratmak ve hem de bürokratik engelleri ortadan kaldırmaktır. Özellikle kamunun bu alandaki görevi cazip ekonomi politikası şartlarını sağlamak ve gelinen süreci kontrol etmekten geçmektedir, yani devlet girişimcilik özgürlüğünü, yasal güvenliği, iyi eğitilmiş personeli, değişken iş piyasasını, yüksek kaliteli altyapıyı, sürdürülebilir maliye politikasını, ılımlı vergi politikasını, güçlü eğitim ve araştırma kapasitesini ve yüksek yaşam kalitesi ile bağdaştırmak zorundadır. Bu gelişmeler ışığında ekonomide hızlı dijitalleşmenin sağlanmasıyla birlikte verimlik artacak, sanayicinin rekabet gücünü yükseltecek ve yeni iş alanlarının yaratılmasına olanak tanınacaktır. Covid 19 pandemi krizi de dijitalleşmeyi oldukça hızlandırmış ve yaşantımızın tüm alanlarını etkilemiştir.
\end{abstract}

Anahtar kelimeler: Dijitalleşme, yeni teknolojiler, işgücü piyasaları

\section{Abstract}

Digitization is changing the economy and the world of work. It's affecting all sectors of the economy. This change is based on new Technologies. Information and communication Technologies are being driven by the network infrastructure of the economy with effective and powerful computerization. Digitalization affect create structural change and economic growth and it is a change for the business World. The task of the state in this direction is removing bureaucratic obstacles. In the light of these developments, with the rapid digitalization in the economy will increase the productivity and the competitiveness power of the industrialists will be able to increase and new business areas will be created. In particular, the task of the government in this area is to provide attractive economic policy conditions and control of the economic process, ie state entrepreneurship freedom, legal security, well-trained staff, variable labor market, high quality infrastructure, sustainable fiscal policy, moderate tax policy, strong training and research capacity and must provide high quality of life. In the light of these developments, by ensuring rapid digitalization in the economy, productivity will increase, the competitiveness of the industrialist will be increased and new business areas will be created.

Key words: Digitalization, new Technologies, labor markets

Erol, E.D. \& Erol, I. (2021). Dijital Teknolojik Gelişim ve Covid 19 Salgınının İstihdam Piyasasına Etkisi. Journal of Academic Value Studies, 7 (4), $451-$ 457. http://dx.doi.org/10.29228/javs.51957

\footnotetext{
* Bu makale, 9-11 Haziran 2021 tarihlerinde Bişkek/Kırgızistan'da gerçekleştirilen 2. Uluslararası İktisadi ve İdari Bilimler Kongresi'nde sözlü olarak sunulan bildirinin genişletilmiş halidir.

${ }^{* *}$ E-mail: ecehan.erol@hotmail.com (Corresponding Author)
} 


\section{Giriş}

Dijitalleşme teriminin birçok anlamı bulunmaktadır. Dijital sektörün dar ve geniş anlamlı tanımları mevcuttur, ancak burada yapılan tanım 2007 yılında OECD’nin yapmış olduğu tanımdır (OECD, Information Economy 2007).

Dar anlamlı tanım açııından bakıldığında üçüncü devrim veya dijital dönüşüm, bilgi ve iletişim tekniklerinin dijital ortama aktarıması, aletlerin ve araçların dijital modifikasyonu olarak tanımlanmaktadır. Geniş anlamlı tanımda ise bilgi cağını yakalama veya bilgisayarlaşma olarak bilinmektedir.

Dijital teknolojiler yaşantımızı ve ulusal ekonomilerdeki verimliliği değiştirmekte ve yeniliklere olan bağımlılı̆̆ı arttırmaktadır. İşletmelerin ürün ve hizmet üretimlerini etkilemekte, yenilikleri hızlandırmakta, işgücü miktarı ve kalitesi ile kamu alanları arasındaki etkileşimi de hızlandırmaktadır. Dijital teknolojiler işletmelerin verimliliklerini ve dolayısıyla insanların yaşam düzeylerini arttırma potansiyeline sahiptir. Örnek olarak bulut bilgisayarlar işletmelere esnek veri toplama, depolama ve kullanmaya erişim sağlamakta, çevrimiçi platformlar, tüketiciler, şirketler arasındaki etkileşimi optimal sağlayabilmekte, yapay zeka ise karmaşık problemleri daha basit otomatik konuma taşıyabilmektedir (OECD 2017).

Dijital cağın iki temel özelliği göze çarpmaktadır (Düll 2016;6):

*Bilgisayarın 0/1 kodlaması için bilgilerin depolanması ve yazılım sistemiyle makine algoritmalarının tanımlanması ve bunun için dijital kodların kullanılması önemlidir.

* Enformasyonların, yani bilgilerin sayılaştırılması yazı sisteminin icadından beri bilgi sisteminin en temel yeniliği olarak görülmektedir.

Bilgiler sadece değiştirilmiş kodların saklanması ve okunmasına hizmet etmemekte, daha çok elektronik dijital makineler bilgiyi anlayabilmekte, karşı reaksiyon gösterebilmekte ve gerekli görüldüğünde bilgileri aktarabilmektedir. Programlama kodları geliştikçe, sensörler ve kontrol teknolojisi iyileştikçe makineler kendiliğinden daha yeterli konuma taşınmakta, verimlilik oranları artmakta ve kendiliğinden hareket etme imkanı elde edilmektedir. Dijital veri tabanlarının büyümesiyle birlikte, dijital teknolojilerin uygulama alanları genişlemekte ve büyük bir dinamizme sahne olan süreç güçlenerek devam etmektedir (Dinges ve diğ.2017:4- Sträter ve Bengler 2019). Dijital teknoloji bir taraftan birçok alanda insan emeğinin yerini alma potansiyelini geliştirirken, diğer taraftan neredeyse ekonominin tüm faaliyet alanlarında verimlilik artışını körüklemektedir. Bilgi teknolojilerinin iş yerlerine olan tamamlayıcı veya ikame edici etkisi önemlidir. Yeni teknolojiler ya işgücünü tamamlayıcı bir nitelik taşıyacak, ya da teknolojiler iş gücünün yerini alacaktır. Burada önemli olan konu, önümüzdeki 15 yıl içinde öyle bir teknolojik dalga yaşayacağız ki, işyerlerinde olan teknik büyümeden çok salma etkisinin daha büyük olacağı tahmin edilmektedir. Salma etkisi yeni teknolojilerin işyerlerine uygulanmasıyla kendini gösteren teknolojik işsizliği ve iş yerlerindeki iş yeri tasarrufunu ifade etmektedir. Ancak istihdam piyasasında hem şanslar ve hem de riskler karşı karşıyadır. Bilgi teknolojileri sadece teknolojik işsizliğe neden olmaz, aynı zamanda yeni iş yerlerini de yaratırlar (Hütner 2020:18-19; Bundesministerium 2020).

\section{Teknolojik Gelişmenin Temel Alanları}

Dijital teknoloji dört temel alanda kendini göstermektedir (Führer 2016:25).

*Bilgilerin Dijitalleşmesi, Bilgi Platformları

*Yazılım, Yapay Zeka, Büyük Veri Analizi

*Depolama ve İletim Teknolojisi, İnternet Iletişimi, Bulut Bilişim

*Sensör Teknolojisi, Kontrol Teknolojisi ve Robot Teknolojisi

Bilgilerin dijitalleşmesi o kadar çok geliştirildi ki, yeni bilgiler dijital ortamda hizmete sunulmaktadır. Internet ortamında yeni bilgilere Google arama, Ticaret Platformları ve Amazon gibi arama sitelerinden ulaşılmaktadır. Bu bilgilerin çoğu internet ortamında ücretsiz olarak hizmete sunulmaktadır.

Internet yazıımı bilgileri makinelerde hazır hale getirmekte, yaşantımızın ve iş alanlarımızın her yönünü etkilemektedir. Yazılımlar olmadan artık ekonomi, kamu ve özel yaşam fonksiyonlarının yerine getirilmesi mümkün değildir. 
Yeni araştırmalar yapay zeka ve büyük veri analizleri üzerine yoğunlaşmıştır. Depolama ve iletim teknolojisi elektronik internet ortamında makinelerle bilgilerin değişimini sağlamakta ve bu alandaki sıkıntılar geniş bant ağ ortamı sayesinde çözülmektedir.

Son olarak üretimde otomasyon ve robot teknolojisinin geliştirilmesi, yapay zeka sistemleri ve kontrol teknolojileri alanlarındaki araştırmalar devam etmektedir.

\section{Dijitalleşme Devriminin İşgücü Piyasaları Üzerine Etkisi}

1990'lı yıllarda Nobel ödülü alanlardan ekonomik büyümenin duayeni Robert Solow bilgisayar devriminin yaşantımızın her alanında görüleceğini, fakat sadece istatistiklerde bulunamayacağını ifade etmişti.

Mc Kinsey'e göre teknik ilerlemenin ekonomik verimliliğe yansımamasının beş nedeni bulunmaktadır (Manyika ve diğ. 2017):

a. Bilişim teknolojilerindeki fiyat gelişmeleri geleneksel metotlarla ölçülememekte ve var olan değerler çarpıtılmaktadır.

b. Dijitalleşme sonucunda sadece yüksek katma değere ulaşılamamakta ve bu sonuç istatistiklere yansıtılamamaktadır. Tüketici refahının artmasında rol oynayan skpe, google, e-ticaret ve benzeri hizmetler ücretsiz olarak hizmete sunulmaktadır.

c. Teknolojik ilerleme zaman gelişmesine bağlı olarak gecikmeli olarak hesaplanmakta, ekonomide 10-15 sene içinde gerçekten etkisini gösterebilmekte ve sayılara aktarılabilmektedir.

d. Dünyada dijital işletmeler ile bunun dışında kalan diğer işletmeler arasında büyük fark bulunmakta, hem ABD'de ve hem de Avrupa'da bazı firmalar verimlilik alanında en ön saflarda yer almakta, diğer firmalar da gecikmeli olarak onları takip etmektedir. Verimlilik alanında bir gerileme söz konusu olduğunda, bu duruma bağlı olarak dijitalleşme alanındaki verimlilik kazancı çok yavaş toplam ekonomiye yansıtılmaktadır.

Bu gün enformasyon teknolojilerinin sanayi sektörüne yansıması ile yaşanan verimlilik patlaması, 1990'ı yıllardaki "New Economy" Yeni ekonomi düşüncesi ile başlamıştı. Daha sonra devam eden dönemdeki bilgisayar devriminde ölçüm problemi çözülmüş, bu alandaki gelişmeler verimlilik istatistiklerine yansımış, gerçekten ekonomide büyük yeniliklerin yaşandığı ortaya çıkmış ve ekonomiyi derinden etkilediği ispatlanmıştır.

Aradan yaklaşık 20 yıl geçtikten sonra dünya ekonomisi yine yeni bir gizemle karşı karşıyadır. Avrupa ve ABD'de ölçülen düşük verimlilik artış oranlarına karşın sanayide otomasyonun artması, dijitalleşmenin çoğalması ve tüm ekonomik verilerin kayıt altına alınması sürecinin devam etmesi tüm ekonomileri derinden etkileyecektir. Tüm dünyada büyük veri bankasının oluşturulmaya çalışıması ve dijitalleşme olgusu şirketler dünyasını önemli ölçüde etkileyecektir.

\section{Teknolojik ilerleme ve İstihdam}

Burada açıklanması gereken soru, acaba toplam verimliliğin istihdama etkisi konusunda optimist veya pesimist bir görüşe sahip olabilir miyiz? Teknik ilerleme bir taraftan sanayi sektöründe işyerlerinin yok olmasını sağlarken, diğer taraftan yeni işyerlerinin oluşmasına da zemin hazırlamıştır. Birinci teknoloji devrimi 18 yy başlamış, ikinci teknoloji devrimi de 20 yy başlarından itibaren etkisini göstermiş ve insanların fiziksel gücünü arttırmaya yönelmiştir (Soyak 2017:71). Geçmiş dönemlerde makineler iş̧̧ilerin çalışmalarını tamamlayıcı bir nitelik taşıyordu. Zamanımızda kendini hissettiren dördüncü sanayi devrimi sadece zihinsel performansa yönelik ve kendi kendine düşünebilen robotlardan oluşacaktır. Ancak kendi kendine düşünen makinelerin iş̧̧i emeğini tamamlayıcı bir nitelik taşıyıp taşımayacağı konusu hala belirsizliğini korumaktadır. Uzmanların görüşüne göre bilişim teknolojileri birçok iş yerindeki işgücünün niteliğini değiştirebilecektir (Kuba 2017:3). Rutin iş faaliyetleri yeni teknolojiler tarafından baskı altına alınabilecek, fakat rutin karakter taşımayan iş faaliyetleri kazançlı çıkabilecektir. Rutin olmayan iş faaliyetleri yapılandırılmamış problemlerin çözümünde, yani ince motor becerileri ile karmaşık iletişim hizmetlerini kapsamaktadır. Dijital ilerleme o kadar hızlı ki, muhtemelen robotlar bu rutin olmayan iş alanlarını kapsayacaklardır.

Küresel çerçevede dijital dönüşüm sayesinde uzak bölgelerdeki insanlarla daha rahat ilişki sağlanacak, toplumun bilgi düzeyi artacak ve yeni teknolojilerin bulunmasındaki ivme hızlanacaktır. Almanya'da çalışanların \%54'ü internet bağlantılı bilgisayarlarda çalışmakta ve dörtte bir üretim de tam otomasyonla veya yüksek düzeyli otomasyonlarla gerçekleşmektedir. Dijital teknolojiler önümüzdeki yıllarda sanayi sektöründe etkinliliğini daha da arttıracaktır. Artık akıllı 
robotlar, yapay zeka sistemleri ve bunlara bağlı internet ağları dördüncü sanayi devriminin vazgeçilmez unsurları haline dönüşmektedir (Schwarzbauer 2017:2).

Emek gücünün ekonomik büyümeye olan etkisinin gün geçtikçe azaldığını görüyoruz. Buna karşın dijital sermaye küresel ölçekte önemini daha da arttırmaktadır. Özellikle daha az kalifiye olan iş̧̧ilerde işsizlik oranları artmakta veya daha düşük ücret düzeyi uygulanmaktadır. İmalat sanayilerinde el emeği ile çalışan işyerlerinin birçoğu otomasyona geçmekte ve diğer hizmet sektörüne bağıı işyerlerinde de en kısa sürede otomasyona geçilecektir.

Teknolojiler bir taraftan yeni iş yerleri yaratırken, diğer taraftan eski iş yerlerinin de otomasyona geçmesini sağlamaktadır. Şimdiye kadar iş piyasasındaki net istihdam etkisi pozitif görünümlüdür, yani teknolojilerin yeni işyeri yaratma etkisi, eski işyerlerinin yok olmasından daha büyüktür ve bu alanlarda işsizlik oranlarında pek artış olmamıştır, çünkü yeni uygulama alanı bulan teknolojiler yeni ş yerleri yaratmışlardır. Özellikle küresel alanda perakende sektöründe ve imalat sanayiinde kendini gösteren makineleşme ve dijitalleşme yeni iş yerleri yaratmış ve bu nedenle de işsizlik artmamıştır (Herzog-Stein 2016:5; Bundesministerium:5).

Dijital başlangıç şirketlerinin gücü o kadar da fazla değildir. Oxford üniversitesindeki bazı araştırmacıların tahminlerine göre $A B D$ istihdam piyasasının \%47 oranındaki istihdam ilişkileri yakın bir gelecekte bilgisayar faaliyetleri tarafından gerçekleştirilecektir.

Avrupa Düşünce kuruluşu olan Bruegel enstitüsünün Avrupa İstihdam Piyasası için yaptığı araştırmaya göre, Almanya'daki istihdam piyasasının \%51'i, i̇spanya istihdam piyasasının \%55'i, ve Portekiz istihdam piyasasının \%59'u değişime uğrayacak, özellikle perakende sektöründeki, hizmet sekmentlerindeki ve büro hizmetlerindeki iş yeri kayıplarının yeni teknolojilerin etkisiyle büyük çapta olacağı beklenmektedir (Bruegel İnstitut 2017).

Deutsche Industrie- und Handelskammer (DIHJK) 2014 yılında toplam Alman işletmelerinin \%94'üne yapmış olduğu dijital dönüşüm konusundaki ankete göre, işletmelerin \%23'ü dijital gelişmeyi pozitif olarak değerlendirmiş ve çalışanlarında ilave artışa gideceklerini vurgulamış, işletmelerin \%62'si çalışanlarında herhangi bir değişiklik olmayacağını söylemiş ve işletmelerin \%15'i de çalışanlarında azalmaya gidebileceklerini ortaya koymuştur (Schumann 2014 ve Rump ve Bretschopf 2017).

Ülkemizde Ulaştırma Denizcilik ve Haberleşme Bakanlığı Ulusal Genişbant Stratejisi ve Eylem planı (2017-2020) hazırlamış, her eve geniş bant erişimi, geniş bant internet kullanımının yaygınlaştııılması ve bunların altyapısının geliştirilmesi konularında bir rapor hazırlamıştır (Ulaştırma ve Denizcilik Bakanlığı 2017).

OECD'nin 2017 yılında yaptığı bir araştırmada OECD ülkelerinde iş verimliliği sürekli artan dijitalleşme rağmen azalma eğilimi göstermiştir. Bu durum sadece ölçüm probleminden kaynaklanmamaktadır. Verimlilik artışındaki yavaşlama bir yandan çok faktörlü verimlilikdeki düşük büyümeden ve diğer yandan düşük sermaye birikim oranlarından kaynaklanmaktadır. Küresel finans krizinin etkileri (düşük kredi arzı, maddi ve maddi olmayan yatırımlar, yapısal değişim isteksizliği, işletme dinamizminin kaybolması ve verimlilik artışındaki dalgalanmalar) işletmelerdeki verimlilik artışlarını önemli ölçüde etkilemiştir (OECD 2017).

\section{Covid 19 Krona Krizi ve Dijital Dünya}

2020 yılının başındqn itibaren covid 19 virüsü dünya çapında yayılmaya devam etmekte ve elde edilen tecrübeler bize virüsle nasıl başa çıkılacağını öğretmektedir.

Corona krizinin en önemli iki etkisi iş dünyasında kendini göstermektedir:Öncelikle bu kriz iş dünyasındaki dijital değişimi hızlandırmaktadır.

Almanya'daki iş dünyası anketine katılanların \%85 i işlerin ev ofislerinden veya mobil çalışma olarak dijital iletişim araçlarıyla yapıldığına inanmaktadırlar (Hoffmann ve Wintermann 2020). Uzmanların \%92'si corona krizi işletmelerdeki dijital değişimi hızlandırdığına inanmaktadırlar. Bu alandaki beklentiler krizin sona ermesi durumunda bile dijital hizmetler ve müşteri iletişim kanalları kullanılmaya devam edilecektir (Bock ve diğ 2018:3-4).

Çalışma dünyasının iyileştirilmesinde ekonomik ve politik karar vericilerin zamanında ve uygun ortamda problemleri tanıyarak harekete geçmeleri önemini korumaktadır.

Sanayi sektöründe bürolarda çalışan personelin işlerini evden yapmaya alışmışlardır. Bu strateji de yeni bir yönetim sistemini ortaya çıkarmıştır. Personeli kontrol eden bir yönetici olmadığı halde firmaların işleri dijital ortamda 
ve firma bünyesinden uzakta kendiliğinden yürümektedir. Yalnız bazı işletmeler evden iş yap fikrine hazırlıksız yakalanmışlardır. Mobil cihaz satın alımları ve kurumsal sorunlar dijital iletişimi zorlaştırmıştır.

Diğer açıdan bakıldığında, her kim işletmede çalışıyorsa, o işletmenin bir parçasıdır ve işletme kültürünü özümsemiştir. Ev ofislerinde çalışanlar işletme içi bilgi aktarımından mahrum kalmakta ve firma ici eğitim imkanlarından mahrum kalmaktadırlar. Ayrıca iş yaşamı ile aile ortamı problemleri birbirine karışmakta, iş disiplini bozulmakta ve dinlenme zamanlarına dikkat edilmemektedir.

Kovid 19 krizi tüm dünya ülkelerinde toplam arz miktarının düşmesini sağlamış ve krizin etkilerini zayıflatıcı tedbirler, hizmet sektörü işyerlerinin geçici kapatılması, şehirlerarası ulaşımın kısıtlı olarak sağlanması, karantina tedbirleri gibi faaliyetler iş hacminin daralmasına mal ve hizmet üretiminin düşmesine neden olmuş ve sonuçta toplam gelirlerde bir azalmaya yol açmıştır. Bir çok iş yerinin kapalı olması toplam arz miktarını daraltmış, satış ve kar marjlarını da önemli ölçüde etkilemiş, iş̧̧ilerin ücret gelirlerini de daraltmıştır.

Pandemi krizinden uluslararası ürün tedarik zincirleri de etkilenmiş ve uluslararası ticaret hacmini önemli ölçüde etkilemiştir. Hammadde ve ara malı tedarikinde oluşan zorluklar ve gecikmeler ülkelerin üretim hacimlerin daraltmıştır. Ekonomileri dış dünya ile daha çok entegre olmuş veya daha çok dış dünyaya bağımlı olan ülkeler bu krizden daha çok zarar görmüşlerdir (Petersen ve Bluth2020:23-24).

Tüm ülkelerde oluşan negatif arz şoku gelişmesi belirli bir zaman diliminde ekonomi tarafından obsorbe edilebilecektir, ancak bu kriz ne kadar uzun sürerse gelir ve servet değerlerinde erime ile firma kapanmaları gündeme gelebilecektir. Ayıca devletin borç yükünün giderek artması da toplam talep miktarı desteklemeye yetmeyecektir.

Bu yaşanan süreçte pandemi ile savaşta ekonomik faaliyetlerin mümkün olduğunca evden dijital ortama taşınmasının politik olarak desteklenmesi ve bu alanda yapısal değişimin zorunlu olduğu kanısının yaygınlaşması dijitalleşmenin önemini daha da arttırmaktadır. Pandemi krizi döneminde uzaktan çalışma ve internet üzerinden pazarlama alanlarında daha başarılı olmaktadırlar.

Toplumun belirli kesimlerinde digitalleşme ne kadar gelişmiş ise, kriz ortamındaki başarı o denli artmaktadır. (Bundesministerium 2020).

Avrupa Birliğindeki araştırmalar gösteriyor ki, digitalleşme ne kadar çok gelişirse, kriz ortamından çıkmak o denli hızı olmaktadır. Daha önceki dönemlerde dijitalleşmeyi ön plana alan ve bu alanda yatırımlarını gerçekleştiren işletmeler pandemi krizine zamanında uyum sağlayarak karlı konuma geçebilmişlerdir.

\section{Sonuç}

Mega trend acısından değerlendirildiğinde iki gelişmeyle karşı karşıya kalınmaktadır:

Korona pandemi krizi dijitalleşmenin hızlandırılması açısından bir katalizatör görevini üstlendiği ortaya çıkmaktadır.

Dijital teknolojiler ticaret, hizmet ve üretim sektörlerinde artan oranlarda gelişim süreci içinde olacak ve değişime uğrayacaktır. Pandemi nedeniyle kısa süreli işsizliğin artacağı ve pandemi sonrası yeni teknolojilerin yeni iş olanakları sağlayacağı düşünülmektedir. Ayrıca kriz dönemi içinde sanayi sektöründe artan dijitalleşmeye rağmen verimlilik alanlarında düşmeler yaşanmış, küresel kriz sonrası önemli ölçüde verimlilik artışlarının olacağı tahmin edilmektedir.

Ülkelerin sanayi sektörlerinin uluslararası alandan hammadde veara malları tedarikinde gecikmeler yaşanmakta ve dış dünyaya olan bağımlılık azalmaktadır.

Birçok ülke kilit sanayi sektörlerini (Robot teknolojisi, biyo teknoloji ve dijital teknoloji) desteklemekte, dı̧̧ dünyaya bağımlı olmadan her ülke kendi kilit sanayi sektörlerine öncelik vermektedir. 


\section{Kaynaklar}

Führer, A. S (2016), Wirtschaftspolitische Projektberatung, Digitalisierung, Produktivität und Beschäftigung, 8 November 2016 Wienhttp://www.forschungsnetzwerk.at/downloadpub/streissler-bka-digi2016-studie.pdf

Bock-Schappelwein,J.; Böheim, M.; Christen,E.; Ederer,S.; Firgo,M.; S. Friesenbichler,K.; Hölzl, W.;Kirchner, M.; Köppl, A.; Kügler, A.;Mayrhuber, C.; Piribauer,P.\&Schratzenstaller,M. Politischer Handlungsspielraum zur optimalen Nutzung der Vorteile der Digitalisierung für Wirtschaftswachstum, Beschäftigung und Wohlstand, ÖSTERREICHISCHES INSTITUT FÜR WIRTSCHAFTSFORSCHUNG, https://www.researchgate.net/profile/MathiasKirchner-

2/publication/339028502_Politischer_Handlungsspielraum_zur_optimalen_Nutzung_der_Vorteile_der_Digitalisi erung_fur_Wirtschafts_wachstum_Beschaftigung_und_Wohlstand_WIFO/links/5e39743a92851c7f7f1b3f16/Poli tischer-Handlungsspielraum-zur-optimalen-Nutzung-der-Vorteile-der-Digitalisierung-fuer-Wirtschafts-wachstumBeschaeftigung-und-Wohlstand-WIFO.pdf

Bundesministerium (2020)Digitalisierung und Wirtschaftsstandort, Studie, Digitalisierung-Konjunktur Motor in der Krise- Wien Juni 2020/Desktop/Accenture-Digitalisierung-Konjunkturmotor-in-der-Krise-DE.pdf

Bruegel İnstitut (2017) Ein Blick in die Zukunft der Arbeit in Europa; Die Zukunft der Arbeit in Europa:Mehr Gewinner und weniger Verlierer, http://gereports.de/post/161620136154/die-zukunft-der-arbeit-in-europa-mehrgewinner.

Dinges,M.;Leitner K.;Dachs B.;Rhomberg W.\&Wepner,B (2017);4.0 Beschäftigung und İndustrie, Technologischer Wandel und die Zukunft des Arbeitsmarkts, Bundesministerium für Verkehr, İnnovation und Technologie, Wien 2017.

Düll,Nicola (2016); Digitalisierung der Arbeitswelt- grundlegende thesen içinde:

Düll,Nicola (Hg)Arbeitsmarkt, Digitalisierung der Arbeitswelt, fachexpertisen zur Prognose 2016, im Auftrag der Bundesministerium für Arbeit und Soziales. W.Bertelsmann Verlag Bielefeld.

Hoffmann,A.\&Wintermann,O, (2020) Die Auswirkungen der corona -Krise auf die Arbeitswelt:Was bleibt und was nicht?,Zukunftstudie, Downloads/die-auswirkungen-der-corona-krise-auf-die-arbeitsweltb173ecd6b4f3419d979d799e9c35ba1a1d6adfc2.pdf.

Hütner, M., (2020)Potenzielle und Umsetzung der Digitalisierung auf Unternehmensebene, Wirtschaftsdienst, Konferenzhefte, Inormationszentrum Leibniz, DOI: 10.1007/s10273-020-2610-x, Desktop/Hüther2020_Article_PotenzialeUndUmsetzungDerDigit.pdf.

Kuba, Sylvia (2017); Arbeitsmarkteffekte der Digitalisierung, Ak Policy Paper, April 2017 https://media.arbeiterkammer.at/wien/PDF/studien/digitalerwandel/AK_Policy_Paper_Nr.7_Arbeitsplatzeffekte. pdf.

Manyika,J.;Chui M.;Miremadi M.;Bughin J.;George K.;Willmott P.\&Dewhurst M.; (2017)A Future That Works2017: Automation,Employment and Productivity, Mc Kinsey Global Institute

OECD (2007) İnformation Economy-Sector Definitions Based on the International Standard Industry Classification (ISIC 4)

OECD (2017) 2.Digitalisierung und Produktivität: komplomentare Themen, OECDilibrary, Wirtschaftsausblick, https://www.oecd-ilibrary.org/sites/70409513-de/index.html?itemld=/content/component/70409513-de

Pertersen,T.\&Bluth,C. (2020)Megatrend-Report 02:Die Corona Transformation, Wie die Pandemie die Globalisierung bremst und die dijitalisierung beschleunigt,Bertelsmann-Stiftung 2020, MT_MegatrendReport2_Web_2020_DT.pdf (bertelsmann-stiftung.de)

Schwarzbauer, W. (2017); Die Digitale Evolution, Bundesministerium für Wissenschaft Forschung und Wirtschaft, Poicy Brief Nr.34 Mai 2017.

Soyak, A. (2017), Teknolojiye Dayalı Sanayileşme: Sanayi 4.0 ve Türkiye Üzerine Düşünceler, Marmara Sosyal Araştırmalar Dergisi, Sayı11. 
Sträter,O\&Bengler,K. (2019)Postionspapier Digitalisierung der Arbeitswelt2.Arb. Wiss. 73,243*245 https://doi.org/10.1007/s41449-019-00161-2.

Rump, J.\& Bretschopf, K. (2017), HAYS Recruiting experts worldwide HR-Report 2017 Schwerpunkt Kompotenzen für eine Digitale Welt, https://www.hays.de/documents/10192/118775/Hays-Studie-HR-Report-2017.pdf.

Ulaştırma, Denizcilik ve Haberleşme Bakanlığı,Ulusal Genişbant Stratejisi ve Eylem Planı (2017-2020) 2017http://www.sp.gov.tr/upload/xSPTemelBelge/files/IxIRY+Ulusal_Genisbant_Stratejisi_ve_Eylem_Plani_20172020.pdf. 